\title{
Numerical Simulation of the Influence of External Insulation By the Mud on the Convection in the Buildings
}

\author{
Benachour Elhadj, Draoui Belkacem, Asnoune Khadidja, Hasnat Mohamed, Rahmani Lakhdar \\ Energarid Laboratory, Faculty of Science and Technology \\ P.O. P 417. 08000, Road Kenedza University of Tahri Mohamed, Bechar, Algeria \\ benachour_elhadj@yahoo.fr; bdraoui@yahoo.com; kh_asnoune@yahoo.fr; Mohammed.hasnat@yahoo.fr; \\ rahmani_11@yahoo.fr;
}

\begin{abstract}
Building insulation materials are the building materials which form the thermal envelope of a building or otherwise reduce heat transfer. Many insulations are made from petrochemicals and may be a concern for those seeking to reduce the use of fossil fuels and oil.Some insulation materials have health risks, some so significant the materials are no longer allowed to be used but remain in use in some older buildings such as asbestos fibers and urea. Also, the cost can be high compared to traditional insulation. This work presents a study of numerical simulation aiming at the role and the influence of the insulation by the mud Reduced like a local material in the town of Bechar located in the Sahara of Algeria, or one is interested in a comparative study for pursued these goals. In this context, an analogy was used for the functions which are discretized by the finite difference method and integrated in the CFD code which is based on the finite volume method. The effects of various physical parameters such as, the Rayleight number, insulation by the mud as local materials in Sahara of Algeria are studied. The Rayleight nember varies between $10^{3}$ and $10^{6}$, .The obtained results are of fundamental interest and can be relevant for the development of efficient heat exchangers. This technique has proven that the rate of heat transfer is minimized up to $37 \%$.
\end{abstract}

Keywords: Heat transfer in Building, Thermal convection, CFD, Laminar flow, Convection conduction coupling

\section{Nomenclature}

g: Gravitational acceleration $\quad\left[\mathrm{m} / \mathrm{S}^{2}\right]$

Cp: Specific heat at constant pressure $\quad[\mathrm{J} / \mathrm{kgK}]$

h: Heat transfer coefficient $\quad\left[\mathrm{W} \mathrm{m}{ }^{-2} \mathrm{~K}\right]$

$\mathrm{Nu}$ Average Nusselt number $\quad[-]$

t: Time [s]

X, Y: Dimensionless coordinates [-]

U, V: Dimensionless velocity components [-]

$\alpha:$ Thermal diffusivity $\left[\mathrm{m}^{2} / \mathrm{s}\right]$

$\beta: \quad$ Coefficient of expansion $\quad\left[\mathrm{K}^{-1}\right]$

$\lambda: \quad$ Thermal conductivity $\quad[\mathrm{W} / \mathrm{mK}]$

$\mu:$ Dynamic viscosity $\quad\left[\mathrm{Kg} \mathrm{m}^{-1} / \mathrm{s}^{-1}\right]$

$\rho:$ Density $\quad\left[\mathrm{Kg} / \mathrm{m}^{3}\right]$

\section{Introduction}

Thermal comfort is dependent and influenced by a range of environmental factors viz air temperature, radiant temperature, humidity, air movement, metabolic rate or human activity [1,2]. Where buildings are large consumers of energy in all countries, especially in regions with extreme climatic conditions and a substantial share of the energy goes towards heat and cool buildings [3]. The new European energy regulation now considers a high standard of thermal protection in buildings with reasonable energy consumption, satisfactory thermal comfort conditions and low operational costs [4]. Numerous studies across the world have shown the impacts of hot working environments on the working population [5-10]. In the context of climate change and in the view of predictions made by Intergovernmental Panel on Climate Change (IPCC) [11-14], to meet the occupants' thermal comfort requirements traditional systems use a lot of energy. The insulation strategy provides a better thermal climate. Building insulation materials are the building materials 
which form the thermal envelope of a building or otherwise reduce heat transfer, but many insulations are made from petrochemicals and may be a concern for those seeking to reduce the use of fossil fuels and oil. A significant portion and An important part of these not isolated external walls are massive solid brick walls or the thermal perceived in buildings was aimed by some research [15-18].Insulation may be categorized by its composition (natural or synthetic materials), form (batts, blankets, loose-fill, spray foam, and panels), structural contribution (insulating concrete forms, structured panels, and straw bales), functional mode (conductive, radiative, convective), resistance to heat transfer, environmental impacts, and more. Sometimes a thermally reflective surface called a radiant barrier is added to a material to reduce the transfer of heat through radiation as well as conduction. The choice of which material or combination of materials is used depends on a wide variety of factors. Some insulation materials have health risks, some so significant the materials are no longer allowed to be used but remain in use in some older buildings such as asbestos fibers and urea. Also, the cost can be high compared to traditional insulation. The external insulation then becomes often the only possible solution in particular with the old buildings in the Sahara of Algeria. The hygrothermic parameters of the existing wall and reported materials must be well-known to design powerful and durable walls in time. Our study consists in studying the thermal transfer through walls. Two types of walls are studied:

- Uninsulated wall,

- Insulated wall with the mud.

This work presents a study of numerical simulation aiming at the role and at the influence of the insulation by the mud as a local material at the city of Bechar situated in the south west of Algeria, or we are interested in a comparative study for aimed these goals. In this context, an analogy was used for the used functions which are discretised by the finite difference method and integrated in the Fluent software, which is based on the finite volume method. The validation of this procedure was confirmed by comparing some obtained results. The results are presented in the form of distributions of isotherms, Stream lines and the local Nusselt number and average Nusselt number with the aim to study the influence on comfort.

\section{Geometric Configuration}

By giving itself two configurations, the one being described the wall without insulation, and the other one with insulation by the mud. The studied configuration is represented on the figure 1 .

We chose the most widespread construction in the area. The studied room is a structure of a multi-house zone, but in is interested in only one. To simplify the calculation we are interested in a phenomenon of two-dimensional.

The outer walls are simple concrete walls, with the mortar coating outside surface of negligible thickness compared to the thickness of the outside wall. The roof is insulated [supposed adiabatic] and on the bottom floor earth (ground) is a concrete slab with a wooden frame [supposed adiabatic].

Temperatures imposed on interior and exterior walls are captured experimentally in one day of a summer of August the Bechar city to $15 \mathrm{~h} 00$. Then to model this phenomenon this is a square cavity of length $\mathrm{L}$ and a height $\mathrm{h}$. The left and right vertical walls of the cavity are heated to a constant temperature equal to $\mathrm{Tc}=1$ for the dimensionless case, $\mathrm{T}_{\mathrm{f}}$ equal to 0.5 for the dimensionless case, and the other walls are maintained adiabatic.

One will exploit the existence and the absence of the interior insulation to facilitate the comparative study. The thickness of concrete wall $\mathrm{e}_{2}=\mathrm{L} / 20$, and the thickness of the external insulation by the mud is $\mathrm{e}_{1}=\mathrm{L} / 20$.

The factor of the form is $\mathrm{A}=1$.
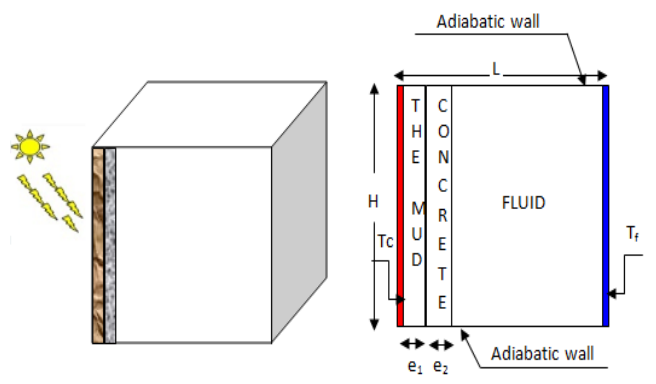

Fig. 1: Schematic of the studied configuration. 
To simplify the problem, assume that:

- The fluid is Newtonian and incompressible.

- The heat dissipation by viscous friction is neglected.

- The Boussinesq approximation is considered

\section{Objectives}

We can express our aim for this study in the following points:

- Study the modelling of the coupling of convection - conduction.

- Study of the effect of the distributionof the heat inside buildings on the convection.

- Comparative study between the construction of buildings with and without insulation.

- Study the effect of the Rayleigh number on the convection in building.

- Test the reliability of the insulation with the Mud as local material.

\section{Mathematical Model}

The fluid is assumed incompressible and obeys the Boussinesq approximation. In these cases, continuity in twodimensional and the equations governing the flow and energy is given by:

\section{Continuity:}

$$
\frac{\partial U}{\partial X}+\frac{\partial V}{\partial Y}=0
$$

\section{X-momentum:}

$$
\frac{\partial U}{\partial t}+U \frac{\partial U}{\partial X}+V \frac{\partial U}{\partial Y}=-\frac{1}{\rho} \frac{\partial P}{\partial X}+v \nabla^{2} U
$$

Y-momentum:

$$
\frac{\partial V}{\partial t}+U \frac{\partial V}{\partial X}+V \frac{\partial V}{\partial Y}=-\frac{1}{\rho} \frac{\partial P}{\partial X}+v \nabla^{2} V+g \beta \frac{\partial T}{\partial X}
$$

\section{Energy:}

$$
\frac{\partial T}{\partial t}+U \frac{\partial T}{\partial X}+V \frac{\partial T}{\partial Y}=\frac{\lambda}{\rho_{C_{p}}} \nabla^{2} T+\frac{1}{\rho_{C_{p}}} \varphi
$$

The derived equation of motion (2) over $\mathrm{Y}$ and the equation of motion (3) by contributing to $\mathrm{x}$. Then, after subtracting the two equations obtained, we obtain the equations dimensionless variables in writing Helmotz in terms of vorticity and stream function formulation are as follows:

$$
\begin{gathered}
\frac{\partial \omega}{\partial t}+U \frac{\partial \omega}{\partial X}+V \frac{\partial \omega}{\partial Y}=\operatorname{Pr} \nabla^{2} \omega+\operatorname{Ra} \operatorname{Pr} \frac{\partial T}{\partial X} \\
\frac{\partial T}{\partial t}+U \frac{\partial T}{\partial X}+V \frac{\partial T}{\partial Y}=\frac{\partial^{2} T}{\partial X^{2}}+\frac{\partial^{2} T}{\partial Y^{2}}+\frac{\varphi}{\rho C p} \frac{L^{2}}{a \Delta T} \\
\frac{\partial^{2} \psi}{\partial X^{2}}+\frac{\partial^{2} \psi}{\partial Y^{2}}=-\omega
\end{gathered}
$$


The stream function and vorticity are related to the velocity components by the following expressions:

$$
U=\frac{\partial \psi}{\partial Y}, V=-\frac{\partial \psi}{\partial X} \text { and } \omega=\frac{\partial V}{\partial X}-\frac{\partial U}{\partial Y}
$$

The dimensionless parameters in the equations above are defined as follows:

$$
\left\{\begin{array}{l}
X=\frac{x}{H}, \quad Y=\frac{y}{H}, \quad U=\frac{u}{u_{i}} \\
V=\frac{v}{u_{i}}, P=\frac{P}{\rho u_{i}^{2}}, T=\frac{T-T_{i}}{T_{c}-T_{i}}, t *=\frac{t}{L^{2} / a}
\end{array}\right.
$$

For solid, we are interested only in the following heat equation:

$$
\frac{\partial T}{\partial t}=\frac{1}{a}\left(\frac{\partial^{2} T}{\partial x^{2}}+\frac{\partial^{2} T}{\partial y^{2}}\right)
$$

\section{Procedure of Simulation}

The numerical calculation was conducted using the GAMBIT and FLUENT software. The numerical procedure used in this work is that of finite volume. It involves the integration of differential equations of mathematical model on finite control volumes for the corresponding algebraic equations.

The SIMPLE algorithm [19] was chosen for the coupling speed pressure in the Navier-Stokes equations on a staggered grid. The convective terms in all equations are evaluated using the schema apwind first order.

The discretization of the time term is made in a totally implicit scheme. The convergence of the solution is considered reached when the maximum relative change of all variables $(u, v, w, p, t)$ between two successive time is not less than $10^{4}$.With an aim of following well any variation of the fields thermal and hydrodynamic, we used a uniform grid of 14241 nodes and 14480 Elements in non stationary mode.

\section{Validation of the Code of Calculation}

\subsection{Validation of the model}

Table1: Comparisons of the results of validation.

\begin{tabular}{|c|c|c|c|}
\hline & Ra $=\mathbf{1 0}^{\mathbf{3}}$ & $\mathbf{R a}=\mathbf{1 0}^{\mathbf{4}}$ & $\mathbf{R a}=\mathbf{1 0}^{\mathbf{5}}$ \\
\hline $\begin{array}{c}\text { Nu (average } \\
\text { number) } \\
\text { (hot wall) }\end{array}$ & present study: & present study : & Present study : \\
& 1.2 & 2.257 & 4.64 \\
\hline $\begin{array}{c}\text { Nu (average } \\
\text { number) } \\
\text { (hot wall) }\end{array}$ & De Vahl Davis & De Vahl Davis & De Vahl Davis \\
& {$[\mathbf{2 0}]$} & {$[\mathbf{2 0}]:$} & 4.52 \\
\hline
\end{tabular}

The computer code was validated on a natural convection problem of stale air in a square cavity with vertical walls differentially heated and adiabatic horizontal walls. Our results were compared with those obtained by De Vahl Davis [20]. The latter dealt with the same problem by adopting the finite difference method with the vorticity-stream function formulation (see Table 1). 


\section{Results and Discussion}

The structure of the flow, the temperature The structure of the flow, the temperature field and heat transfer through the hot wall are discussed in this section. In this study, to target the most important goal, we will show and studied the effect of the insulation by the mud on dynamic and thermal behavior of the fluid in the cavity.

\subsection{Isotherms}

The isotherms are shown in Figures [2-3]. The heat distribution in the cavity is in accordance with the fluid circulation revealed by isotherms and iso currents. Indeed we find a heating fluid from the interface, if it causes the change of the heat distribution in the cavity (see figures) for different numbers of Rayleigh For a fixed value of the number of Prandtl equal 0.71. Gradually, as the Rayleigh number has increased, the isotherms become increasingly wavy and heat transfer increases, so the flow intensifies and natural convection is expanding and predominates (natural convection is predominant).

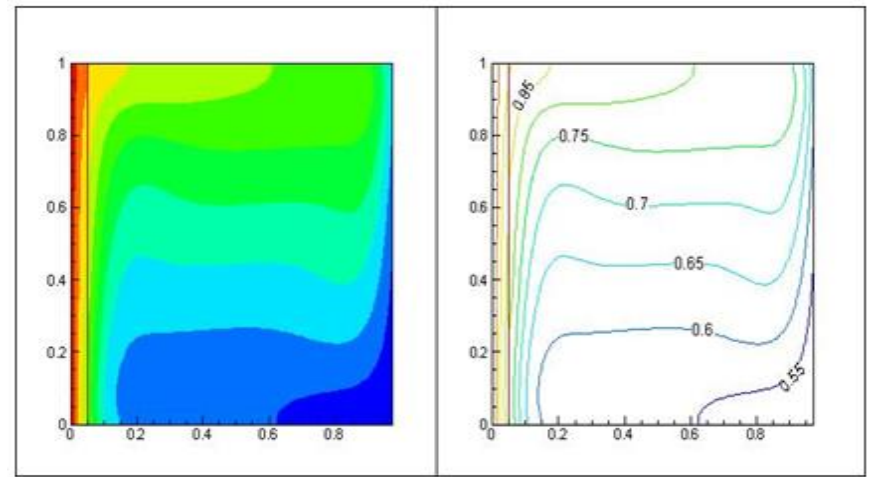

Fig. 2: The isotherms for uninsulated wall, Rayleigh number equal $10^{6}, \operatorname{Pr}=0.71$.

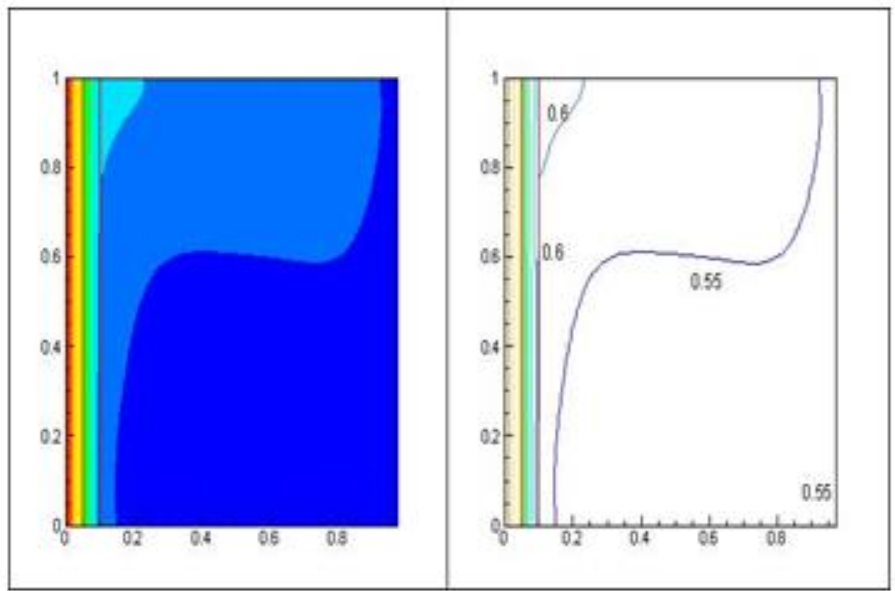

Fig. 3: The isotherms for insulated wall, Rayleigh number equal $10^{6}, \operatorname{Pr}=0.71$.

\subsection{Streamlines}

For the Streamlines figures [not presented here] shows the current lines corresponding to Rayleigh numbers: $10^{3}$, $10^{4}, 10^{5}$ and $10^{6}$ with a value of Prandt $=0.71$, for uninsulated and insulated walls. When $\mathrm{Ra}=10^{3}$, the flow is almost symmetric, we see that there are cells that are closed on itself, the fluid motion was a motion block, which justifies the existence of recirculation zones closer the center of the cavities, the flow lines are substantially parallel to the vertical walls. So also for the representation of flow lines corresponding to the Rayleigh number equal to $10^{4}, 10^{5}$, we find that the current lines are tight at the vertical walls and in the middle, this is due to strong temperature gradient at the vertical walls and thus the flow is parietal which characterizes the large convective heat transfer to the vertical walls. We also observed 
the formation of two cells in the recirculation cavity for $10^{6}$ same. It is also noted in the latter case, the expansion of two areas of recirculation of a cell in the clockwise direction and the other in the opposite direction, with the increase of Rayleigh.

\subsection{Temperature profiles}

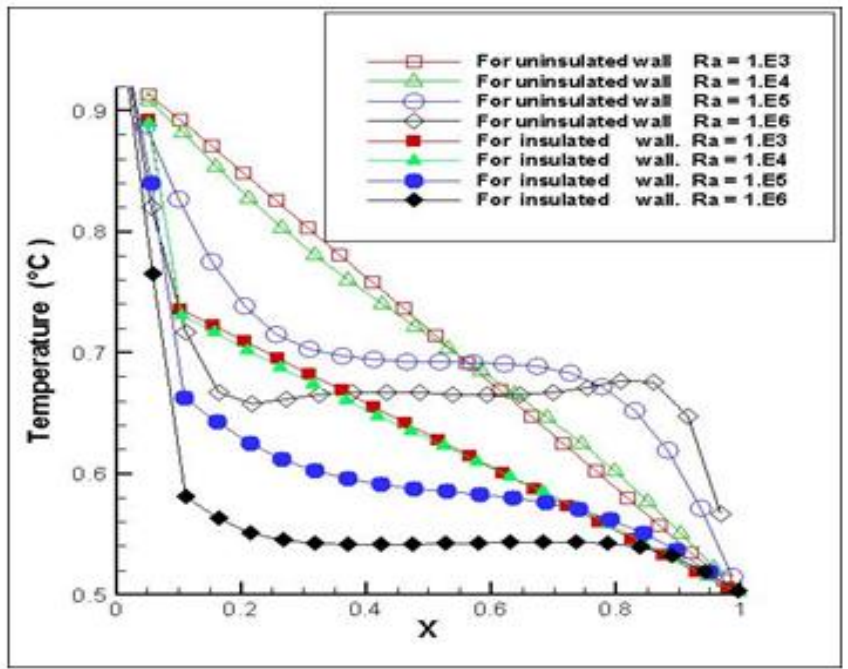

Fig. 4: Dimensionless horizontal temperature profiles for different Rayleigh numbers for uninsulated and insulated walls, $\operatorname{Pr}=0.71, \mathrm{Y}=0.5$.

Observation of the temperature profiles for different values of $y=0.5$ (Figure 4) to Rayleigh leads us to confirm that the increase of temperature takes the form of the parabola is to say, this increase is condensed in the middle irrespective of the number Rayleigh, but it is sensitive, we can say there is a direct proportionality.

\subsection{Nusselt numbers}

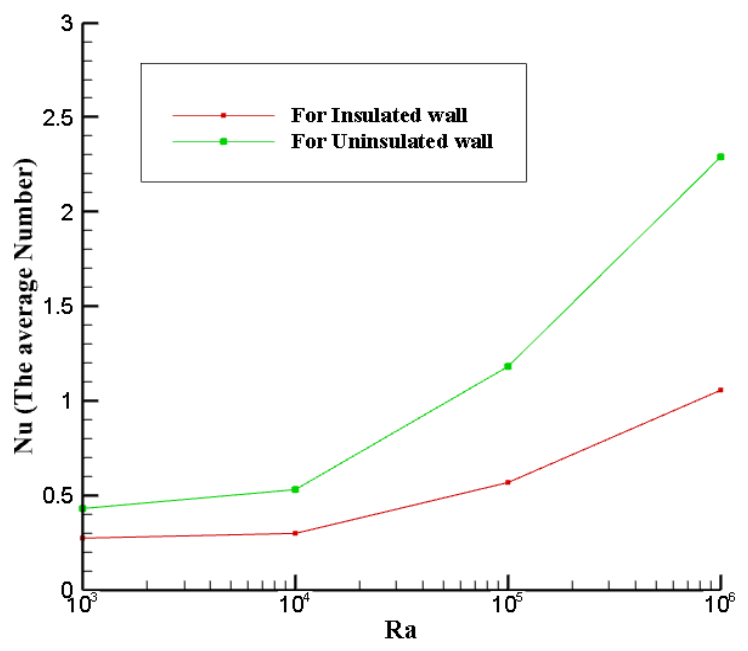

Fig. 5: Profiles of average Nusselt number, for different values of $\mathrm{Ra}=10^{3}, 10^{4}, 10^{5}$ and $10^{6}$, for uninsulated and insulated walls, $\operatorname{Pr}=0.71$.

We report in Figure 5 the influence of the Rayleigh number on average Nusselt number. We found a significant influence of the Rayleigh number. The increase in average Nusselt number is accompanied with the increase of Rayleigh, 
but after the Rayleigh number equal to $10^{5}$, the heat transfer is almost the same, and then represents the better heat transfer in the cavity.

\section{Conclusion}

The idea of this work is based on actual events; the objectives areas of our work was to study the behavior of the air in enclosed with two-dimensional numerical study of natural convection or laminar flow is considered. We are interested by coupling the conduction - convection solving equations governing natural convection written Helmontz's variables $\psi$ and $\omega$ which are discretized by the method of finite deference. We validated the work in the literature for the hydrodynamic and thermal studies in the cavities where he showed good consistency. For our simulation, we presented the streamlines, isotherms and the influence of key parameters such as positioning after the interface and the Rayleigh number. We have shown by this simulation, the following:

1. Convection affects the structure of the isotherms.

2. The temperature of the fluid increases dramatically with increase in Rayleigh number.

3. The external thermal insulation reduces the losses of heat and minimizes the energy needs (request of heating) and thus reduced in fact, at the same time: the invoice, consumption and pollution.

4. The Mud is insulating effective which to guarantee the comfort and the air quality inside the building

5. The external thermal insulation helps to preserve a constant temperature in the internality of your housing winter like summer.

6. The external thermal insulation has a promising future provided that all actors, around the sector of construction are justified and motivated and conscious of the ecological and financial issues.

\section{References}

[1] K. Parsons, Human, Thermal Environment: The Effects of Hot, Cold and Moderate Environment on Human Health, Comfort and Performance, Second Ed. Taylor and Francis, London, 2003.

[2] Y. Epstein and D. S. Moran, "Thermal comfort and the heat stress indices," J. Ind. Health, vol. 44, pp. 388-398, 2006.

[3] P. K. Latha, Y. Darshana, and V. Venugopal, "Role of building material in thermal comfort in tropical climates A review," Journal of Building Engineering, vol. 3, pp. 104-113, 2015.

[4] The European Parliament and the Council of the European Union, "The Energy Performance of Buildings," Council Directive of 2002/91/EC, 2002.

[5] S. A. Arngrïmsson, D. S. Petitt, M. G. Stueck, D. K. Jorgensen, and K .J. Cureton, "Cooling vest worn during active warm-up improves 5-km run performance in the heat," J. Appl. Physiol, vol. 96, pp. 1867-1874, 2004.

[6] A. González, G. Craig, M. J. John, "The cardiovascular challenge of exercising in the heat," J. Physiol, no. 586, pp. 45-53, 2008.

[7] C. Wesseling, J. Crowe, C. Hogstedt, K. Jakobsson, R.A. Lucas, and D.H. Wegman, "Resolving the enigma of the Mesoamerican nephropathy-men - a research workshop summary," Am. J. Kidney Dis, vol. 63, no. 3, pp. 396-404, 2014.

[8] R. S. Bridger, Introduction to Ergonomics, Second Ed. Taylor and Francis, London, 2003, pp. 780.

[9] G. P. Bates, J. Schneider, "Hydration status and physiological workload of UAE construction workers - a prospective longitudinal observational study," J. Occup. Med. Toxicol, vol. 3, pp. 21-26, 2008.

[10] P. Dutta, V. Chorsiya, "Scenario of climate change and human health in India," Int. J. Innov. Res. Dev., vol. 2, no. 8, pp.157-160, 2013.

[11] K. M. Willett, S. Sherwood, "Exceedance of heat index thresholds for 15 regions under a warming climate using the wet-bulb globe temperature," Int. J. Climatol, vol. 32, pp. 161-177, 2012.

[12] T. Kjellström, I. Holmér, B. Lemke, "Workplace heat stress, health and productivity an increasing challenge for lowand middle income countries during climate change," J. Glob. Health Action, 2009.

[13] P. A. Schulte, H. Chun, "Climate change and occupational safety and health: establishing preliminary framew," $J$. Occup. Environ. Hyg., vol. 6, pp. 542-554, 2009.

[14] R. Akhtar, Airies, "Climate change and health and heat wave mortality in India," J. Glob. Environ. Res., vol. 11, pp. 51-57, 2007.

[15] M. S. Mohsen and B. A. Akash, "Some Prospect of Energy Saving in Building," Energy Conversion Management, 
vol. 42, no. 11, pp. 1307-1315, 2001

[16] M. A. Aktacir, O. Büyükalaca, and T. Yılmaz, "A Case Study for Influence of Building Thermal Insulation on Cooling Load and Air-Conditioning System in the Hot and Humid Regions," Applied Energy, vol. 87, no. 2, pp. 599607, 2010.

[17] L. Peeters, R. de Dear, J. Hensen, and W. D'haeseleer, "Thermal Comfort in Residential Buildings: Comfort Values and Scales for Building Energy Simulation,” Applied Energy, vol. 86, no.5, pp. 772-780, 2009.

[18] E. Benachour, et al., "Effect of positioning the heating element on natural convection in a square cavity (habitat type)," International review of mechanical engineering, vol. 4, no. 5, 2010.

[19] S. V. Patankar, Numerical Heat Transfer and Fluid Flow. New York: McGraw-Hill, 1980.

[20] De Vahl Davis G, "Natural convection of air in a square cavity a bench mark numerical solution," 1983. 